\title{
Hypothyroidism and the risk of lower extremity arterial disease
}

This article was published in the following Dove Press journal:

Vascular Health and Risk Management

19 October 2010

Number of times this article has been viewed

\author{
Michael A Mazzeffi' \\ Hung-Mo Lin' \\ Brigid C Flynn' \\ Thomas L O'Connell ${ }^{2}$ \\ David E DeLaet ${ }^{3}$ \\ 'Department of Anesthesiology, \\ Mount Sinai School of Medicine, \\ New York, NY, USA; ${ }^{2}$ Division of \\ Endocrinology, Department of \\ Medicine, University of North \\ Carolina, Chapel Hill, NC, USA; \\ ${ }^{3}$ Division of General Medicine, \\ Department of Medicine, Mount Sinai \\ School of Medicine, New York, \\ NY, USA
}

Background: Although an independent association between hypothyroidism and coronary artery disease has been demonstrated, few studies have examined the association between hypothyroidism and peripheral arterial disease. In the current study, we test the hypothesis that there is an independent association between hypothyroidism and lower extremity arterial disease.

Methods: We retrospectively compared the prevalence of hypothyroidism in patients who had infra-inguinal arterial bypass surgery over a 6-year period with that of a control group of surgical patients who had pure cardiac valve surgery during the same time period. Both unadjusted and adjusted odds ratios were calculated to estimate the association between hypothyroidism and lower extremity arterial disease.

Results: A total of 614 cases and 529 control subjects had surgery during the study period. When comparing all subjects, there was no association between hypothyroidism and lower extremity arterial disease (unadjusted odds ratio $0.88 ; 95 \%$ confidence intervals [CI]: $0.61-1.28$ ). However, gender was found to be a significant effect modifier $(P<0.001)$, and gender-stratified analyses were subsequently performed. In men, there was a positive independent association between hypothyroidism and lower extremity arterial disease (adjusted odds ratio 2.65; 95\% CI: 1.19-5.89), whereas in women there was a negative independent association (adjusted odds ratio 0.22 ; $95 \%$ CI: $0.11-0.46$ ).

Conclusions: Gender is a significant effect modifier for the association between hypothyroidism and lower extremity arterial disease. The association is positive in men and negative in women. Future prospective studies that evaluate hypothyroidism as a risk factor for peripheral arterial disease should consider gender stratification in order to corroborate this finding.

Keywords: hypothyroidism, cardiovascular, peripheral arterial disease, vascular bypass, gender

\section{Introduction}

Thyroid hormone has important effects on the cardiovascular system. It increases heart rate, stroke volume, and cardiac output. It also decreases systemic vascular resistance by dilating arterioles. ${ }^{1,2}$ Overt hyperthyroidism causes a hyperdynamic cardiovascular state, whereas overt hypothyroidism has the opposite effect. In patients with overt hypothyroidism, systemic vascular resistance is increased and hypertension is approximately three times more common than in those who are euthyroid. ${ }^{3}$ Hypothyroidism also leads to arterial stiffening and myxedema of the arterial wall over time. ${ }^{4}$ Despite these well-described phenomena, the long-term effect of hypothyroidism on the development of peripheral arterial disease is not well understood.

Both subclinical and overt hypothyroidism have been clearly linked with dyslipidemia, which is a known risk factor for peripheral arterial disease. ${ }^{5}$ An
Correspondence: Michael A Mazzeffi Department of Anesthesiology, Mount Sinai School of Medicine, I Gustave L. Levy Place, Box 1010, New York, NY 10029-6574, USA

$\mathrm{Tel}+\mathrm{I} 21224 \mid 1518$

Fax +I 2124262009

Email michael.mazzeffi@mssm.edu 
independent association between overt and subclinical hypothyroidism and coronary artery disease has also been demonstrated in patients with normal cholesterol levels, although its degree and clinical significance remain controversial. ${ }^{6-10}$

The most recent publication from the Inter-Society Consensus for the Management of Peripheral Arterial Disease does not recognize hypothyroidism as a risk factor associated with peripheral arterial disease, although some limited evidence suggests that there may be an association between the two. ${ }^{11}$ For example, a study comparing the prevalence of peripheral arterial disease in a group of 18 subclinically hypothyroid patients with that of 231 euthyroid patients found that the prevalence of peripheral arterial disease was significantly higher in hypothyroid patients. ${ }^{12}$ In a second study, women with peripheral arterial disease were found to have significantly higher serum thyrotropin levels than controls. ${ }^{13}$ Elevated thyrotropin levels were strongly correlated with elevated serum cholesterol levels. In two other studies using surrogate outcome measures, hypothyroidism was also demonstrated to be associated with peripheral arterial disease. ${ }^{14,15}$ In the first study, pulse wave Doppler analysis demonstrated an increased arterial stiffness that improved with levothyroxine therapy in hypothyroid patients. In the second study, hypothyroidism was associated with increased intima-media thickness. This finding was demonstrated to be reversible with levothyroxine therapy over a 6-month period. Alternatively, one large prospective study followed 338 patients with subclinical hypothyroidism and 2392 euthyroid patients over a 4-year period and found no increased risk of peripheral arterial disease during that time. ${ }^{16}$

Because conflicting evidence exists in the literature and few studies have examined direct clinical outcomes such as the need for surgical intervention, further studies are needed to clarify this association. In the following study, we test the hypothesis that hypothyroidism is independently associated with lower extremity arterial disease that is severe enough to require surgical intervention.

\section{Methods Study design}

A case-control study comparing adult patients who had lower extremity arterial bypass surgery with a control group of agematched surgical patients was performed. In both the groups, discharge summaries, anesthesia records, and surgical preoperative histories were reviewed. From these records, we specifically recorded any history of diabetes mellitus, hypertension, dyslipidemia, coronary artery disease, and hypothyroidism. We also recorded general demographic data for both groups.

\section{Study subjects}

The study received approval from the Mount Sinai Hospital Institutional Review Board. Subjects were identified using procedure codes from an electronic database. All patients in the case group had lower extremity arterial bypass surgery between January 2002 and January 2008, and controls had isolated cardiac valve surgery during the same time period. Specifically, the case group included femoral-popliteal bypasses, femoral-tibial bypasses, and other femoral-distal bypasses. Both primary and repeat cases were included in our analyses. No subject was counted more than once, even if they had multiple operations during the study period, and only a patient's first operation was included in the analysis. Among controls, we limited subjects to those who were $>60$ years of age in order to age-match the control group with the case group. All patients with a known history of lower extremity arterial disease were excluded from the control group.

\section{Definitions}

Patients were defined as hypertensive if they had a diagnosis of hypertension in their preoperative history or anesthesia record and were receiving antihypertensive medication preoperatively. Diabetes mellitus was defined as having the diagnosis written in either the preoperative history or anesthesia record and receiving either insulin or an oral hypoglycemic medication preoperatively. Dyslipidemia was defined as having a diagnosis of elevated cholesterol or triglycerides written in either the preoperative history or anesthesia record and receiving lipid-lowering therapy preoperatively. A patient was defined as having coronary artery disease if they had any one of the following: cardiac catheterization showing stenosis that required bypass, previous myocardial infarction, positive nuclear stress test, previous cardiac revascularization procedure, previous Q wave on an EKG, or if they were taking nitrates preoperatively for chest pain. Patients were identified as hypothyroid if they had a diagnosis of hypothyroidism written in their preoperative history or anesthesia record and had been taking thyroid hormone replacement preoperatively.

\section{Statistical analysis}

For two group comparisons, $\chi^{2}$ tests were used to compare categorical variables, and Student's $t$-tests were used for continuous variables. The unadjusted odds ratios were calculated by dividing the odds of having lower extremity arterial disease in the exposure group by the odds of having lower extremity arterial disease in the nonexposure group. Logistic regression analysis was performed to assess the 
covariate-adjusted relationship between hypothyroidism and lower extremity arterial disease. The covariates included hypertension, diabetes mellitus, dyslipidemia, ischemic heart disease, age, and gender. Results of the logistic regression analysis were presented as adjusted odds ratios.

Additionally, we assessed all possible two-way interactions between hypothyroidism and the previously mentioned covariates. For any variable shown to have a statistically significant effect modification, we performed further stratified analyses, continuing to adjust for all other covariates. All statistical analyses were carried out using SAS software (SAS Institute, Inc., Cary, NC). For all analyses, $P$ values of $<0.05$ were considered statistically significant.

\section{Results}

\section{All subject analysis}

A total of 614 cases and 529 controls met study enrollment criteria. As shown in Table 1, among all subjects, cases and controls did not differ in gender or age distribution. The prevalence of diabetes mellitus, hypertension, dyslipidemia, and ischemic heart disease was higher in cases than in controls $(P<0.05)$. The prevalence of hypothyroidism, however, was not different between cases and controls $(P=0.50)$.

In the univariate analysis, diabetes mellitus, hypertension, dyslipidemia, and ischemic heart disease all had a positive association with lower extremity arterial disease (Table 2). Hypothyroidism, age, and gender had no significant association. Logistic regression analysis was then performed using age, gender, diabetes mellitus, dyslipidemia, hypertension, and ischemic heart disease as covariates, and again no significant association was found between hypothyroidism and lower extremity arterial disease. However, a highly significant two-way interaction between gender and hypothyroidism was detected $(P<0.001)$. This suggested that gender was an effect modifier for the association between hypothyroidism and lower extremity arterial disease. For this reason, we also performed gender-stratified analysis. No other variable was found to be an effect modifier for the relationship between hypothyroidism and lower extremity arterial disease (all $P>0.05$ ).

\section{Gender-stratified analysis}

After gender stratification, significant differences were still found between cases and controls within individual gender groups. For example, for both genders, the prevalence of diabetes mellitus, hypertension, dyslipidemia, and ischemic heart disease was higher in cases than in controls (Table 1). The prevalence of hypothyroidism was found to be higher in male cases than in controls, whereas the opposite was true in women. Male cases were older than controls, whereas the opposite was true in women.

In the gender-stratified univariate analysis, diabetes mellitus, hypertension, dyslipidemia, and ischemic heart disease were positively associated with lower extremity arterial disease in both gender groups (Table 3). However, the associations between hypothyroidism and lower extremity arterial disease as well as age and lower extremity arterial disease differed by gender. In men, there was a positive association between hypothyroidism and lower extremity arterial disease, whereas in women there was a negative association. In men, there was a negative association between age and lower extremity arterial disease, whereas in women there was a positive association.

When logistic regression analysis was performed, we found a persistent positive association between hypothyroidism and lower extremity arterial disease in men and a persistent negative association in women. Compared to the unadjusted odds ratios, the adjusted ratios were slightly different in magnitude, but remained highly significant in both genders.

Table I Baseline characteristics of subjects

\begin{tabular}{|c|c|c|c|c|c|c|}
\hline \multirow[t]{2}{*}{ Variable } & \multicolumn{2}{|c|}{ All subjects $(n=1 \mid 43)$} & \multicolumn{2}{|l|}{ Males $(n=535)$} & \multicolumn{2}{|c|}{ Females $(n=608)$} \\
\hline & Cases $(n=614)$ & Controls $(n=529)$ & Cases $(n=299)$ & Controls $(n=236)$ & Cases $(n=315)$ & Controls $(n=293)$ \\
\hline Hypothyroidism & $63(10.3 \%)$ & 61 (1I.5\%) & 44 (14.8\%) & $12(5.1 \%)^{*}$ & $19(6.0 \%)$ & 49 (16.7\%)* \\
\hline Diabetes mellitus & $388(63.2 \%)$ & 99 (I8.7\%)* & I88 (62.9\%) & $36(15.3 \%)^{*}$ & 200 (63.5\%) & $63(21.5 \%)^{*}$ \\
\hline Hypertension & $528(86.0 \%)$ & 317 (59.9\%)* & $269(90.0) \%$ & I 33 (56.4\%)* & 259 (82.2\%) & $184(62.8 \%)^{*}$ \\
\hline Dyslipidemia & $332(54.1 \%)$ & $202(38.2 \%)^{*}$ & $163(54.5 \%)$ & 91 (38.6\%)* & $169(53.7 \%)$ & III (37.9\%)* \\
\hline $\begin{array}{l}\text { Ischemic heart } \\
\text { disease }\end{array}$ & $386(62.9 \%)$ & $102(19.3 \%)^{*}$ & I7I (57.2\%) & $58(24.6 \%) *$ & $215(68.3 \%)$ & $44(15.0 \%)^{*}$ \\
\hline Male gender & 299 (48.7\%) & $236(44.6 \%)$ & - & - & - & - \\
\hline$A_{g e} e^{\prime}$ & $71.9(13.1)$ & $72.1(7.8)$ & $74.2(13.2)$ & $71.2(7.9)^{*}$ & $69.8(12.6)$ & $72.7(7.7)^{*}$ \\
\hline
\end{tabular}

Notes: 'All data represent $n=$ absolute numbers (percent of category total) except for age, where the data represent mean age (standard deviation); $* p<0.01$ for comparison between cases and controls within each group. 
Table 2 Unadjusted and adjusted odds ratios of lower extremity arterial disease for study variables

\begin{tabular}{|c|c|c|}
\hline Variable & $\begin{array}{l}\text { Unadjusted } \\
\text { OR' (95\% CI) }\end{array}$ & $\begin{array}{l}\text { Adjusted } \\
\text { OR }^{2}(95 \% \mathrm{CI})\end{array}$ \\
\hline \multicolumn{3}{|l|}{ Hypothyroidism } \\
\hline All & 0.88 (0.6I, I.28) & $\mathrm{n} / \mathrm{a}^{3}$ \\
\hline Male & - & $2.85(1.31,6.16)^{*}$ \\
\hline Female & - & $0.26(0.13,0.52)^{*}$ \\
\hline Diabetes mellitus & $7.46(5.67,9.80)^{*}$ & $5.18(3.82,7.03)^{*}$ \\
\hline Hypertension & $4.1 \mathrm{I}(3.08,5.47)^{*}$ & $2.35(1.66,3.32)^{*}$ \\
\hline Dyslipidemia & $1.93(1.52,2.44)^{*}$ & $0.88(0.64,1.17)$ \\
\hline Ischemic heart disease & $7.09(5.40,9.29)^{*}$ & $5.32(3.91,7.24)^{*}$ \\
\hline Age (per 10 years) & I.0I (0.9I, I.I3) & $0.97(0.85, \mathrm{I} . \mathrm{II})$ \\
\hline Male gender & I.I8 (0.93, I.49) & - \\
\hline
\end{tabular}

Notes: 'Unadjusted odds ratios were calculated using the following method: OR, Odds of having lower extremity arterial disease in exposure group/Odds of having lower extremity arterial disease in nonexposure group; ${ }^{2}$ Adjusted odds ratios were obtained from a multivariate logistic regression model that included all variables in this table; ${ }^{3} \mathrm{For}$ hypothyroidism, an adjusted odds ratio is listed for males and females separately. This is because a significant interaction between gender and hypothyroidism was found $(P<0.00 \mathrm{I})$, demonstrating the effect modification that gender had on the relationship between hypothyroidism and lower extremity arterial disease. $* P<0.05$.

Abbreviations: $\mathrm{Cl}$, confidence intervals; $\mathrm{OR}$, odds ratio

Both diabetes and ischemic heart disease also remained strongly associated with lower extremity arterial disease in men and women in the multivariate analysis (Table 3). The association between hypertension and lower extremity arterial disease, however, was less strong in women (the $P$ value for the two-way interaction between gender and hypertension was $<0.01)$. Dyslipidemia did not show any significant association with lower extremity arterial disease in the multivariate analysis in either gender. Age had a significant association with lower extremity arterial disease in both males and females, but the association differed by gender and the results were opposite of those seen in the univariate analysis.

\section{Discussion}

Our study was designed as a case-control study because it allowed us to identify a large number of patients with lower extremity arterial disease from an existing surgical database. This was more practical than following patients with hypothyroidism prospectively to determine the rate of lower extremity arterial disease over time. When identifying cases and controls, we used the same surgical database. An advantage of this design is that subjects in both groups share a comparable level of accuracy and quality of data. The availability of specific demographic and clinical information was similar for both groups, and we used consistent methodology in applying the definitions described in our methods.

A potential limitation of any case-control study is misclassification of subjects. The result of misclassification is typically to bias toward the null hypothesis. As such, the finding in our study among all subjects of no statistically significant association between hypothyroidism and lower extremity arterial disease could have been a result of misclassification. Specifically, if a large number of controls had undiagnosed lower extremity arterial disease, such misclassification would bias our results toward the null association. However, in our control group, all patients had a preoperative cardiac catheterization, allowing us to determine the prevalence of coronary artery disease in that group with a high level of accuracy. This is helpful in estimating the prevalence of undiagnosed peripheral arterial disease because previous studies have reported a high rate of concurrence between the two diseases (between 50\% and $90 \%) .{ }^{17,18}$ In our control group, we found a prevalence of coronary artery disease of $19 \%$, less than the expected rate of $40 \%-60 \%$ among elderly subjects in the general population. ${ }^{19,20}$ Therefore, we believe that it is unlikely that a high rate of undiagnosed lower extremity arterial disease among control subjects biased our results toward the null.

The differing association between hypothyroidism and lower extremity arterial disease in men and women is interesting, and to our knowledge, no prior study has demonstrated such a gender-specific difference. Because our

Table 3 Unadjusted and adjusted odds ratios of lower extremity arterial disease for study variables by gender

\begin{tabular}{|c|c|c|c|c|}
\hline \multirow[t]{2}{*}{ Variable } & \multicolumn{2}{|l|}{ Males } & \multicolumn{2}{|l|}{ Females } \\
\hline & $\begin{array}{l}\text { Unadjusted } \\
\text { OR' }(95 \% \mathrm{CI})\end{array}$ & $\begin{array}{l}\text { Adjusted } \\
\mathrm{OR}^{2}(95 \% \mathrm{CI})\end{array}$ & $\begin{array}{l}\text { Unadjusted } \\
\text { OR' }(95 \% \mathrm{CI})\end{array}$ & $\begin{array}{l}\text { Adjusted } \\
\text { OR }^{2}(95 \% \mathrm{Cl})\end{array}$ \\
\hline Hypothyroidism & $3.23(1.67,6.28)^{* *}$ & $2.65(1.19,5.89)^{*}$ & $0.32(0.18,0.56)^{* *}$ & $0.22(0.11,0.46)^{* *}$ \\
\hline Diabetes mellitus & $9.41(6.15,14.4)^{* *}$ & $8.04(4.94,13.1)^{* *}$ & $6.35(4.43,9.11)^{* *}$ & $3.99(2.60,6.13)^{* *}$ \\
\hline Hypertension & $6.94(4.40, \text { I I } .0)^{* * *}$ & $4.33(2.54,7.39)^{* *}$ & $2.74(1.89,3.98)^{* *}$ & $1.35(0.83,2.20)$ \\
\hline Dyslipidemia & $1.92(1.36,2.72)^{* *}$ & $0.91(0.58,1.43)$ & $1.92(1.39,2.66)^{* *}$ & $0.86(0.56,1.33)$ \\
\hline Ischemic heart disease & $4.10(2.82,5.96)^{* *}$ & $2.72(1.74,4.26)^{* *}$ & $12.2(8.17,18.1)^{* *}$ & $11.4(7.17,18.2)^{* *}$ \\
\hline Age (per 10 years) & $0.79(0.67,0.92)^{* *}$ & I.43 (I.16, I.77) $)^{* *}$ & I.3I (I.I2, I.53)** & $0.68(0.56,0.83)^{* *}$ \\
\hline
\end{tabular}

Notes: 'Unadjusted odds ratios were calculated using the following method: OR, Odds of having lower extremity arterial disease in exposure group/Odds of having lower extremity arterial disease in nonexposure group; ${ }^{2}$ Adjusted odds ratios were obtained from a multivariate logistic regression model that included all variables in this table. $* P<0.05 ; * * P<0.01$.

Abbreviations: $\mathrm{Cl}$, confidence intervals; $\mathrm{OR}$, odds ratio 
study included a large number of subjects, this difference is difficult to ignore. The mechanism by which hypothyroidism may confer differential vascular risk by gender is unclear. In the United States, women tend to be screened and treated earlier for hypothyroidism than men. ${ }^{21}$ This could explain in part why hypothyroidism was associated with lower extremity arterial disease in men, but not in women. Men may not be screened as early as women, and prolonged uncorrected hypothyroidism may lead to greater vascular risk. However, this phenomenon alone cannot fully explain our study results, as we found a negative association between hypothyroidism and lower extremity arterial disease in women. One explanation might be that earlier identification of hypothyroidism in women leads to more aggressive and earlier modification of other vascular risk factors, but this is speculative and should be further evaluated in prospective studies.

In our study, both diabetes and hypertension were more strongly associated with lower extremity arterial disease in men than in women. A few previous studies have examined the gender-specific impact of risk factors on the development of cardiovascular diseases in men and women. In one large prospective cohort study of over 18,000 patients, the relative risk of myocardial infarction was higher in women with diabetes, hypertension, and left ventricular hypertrophy than in men with the same risk factors. ${ }^{22}$ Hypothyroidism was not examined as a risk factor in that study.

The strengths of our study are the large number of subjects and the consistency of data collection methods and definitions between groups. Our study also has limitations. First, we were unable to accurately obtain data regarding tobacco use among subjects, because tobacco use data were not consistently found in the surgical preoperative history and anesthesia record. Second, because of the retrospective nature of our study and the fact that not all patients received primary care at our center, we do not have laboratory data to confirm medical diagnoses such as diabetes mellitus and dyslipidemia or to assess the adequacy of thyroid replacement in subjects with hypothyroidism. However, the objective of this study was to test the association between the diagnosis of hypothyroidism and lower extremity arterial disease regardless of adequate hormone replacement. It is possible that early and proper hormone replacement may decrease the risk of lower extremity arterial disease in patients with hypothyroidism, and this is an area that should be explored in future studies. Further, we used similar criteria to define diabetes mellitus and hypertension in our study, and data regarding duration of disease or adequacy of treatment were similarly lacking for these two conditions. Nevertheless, both conditions were strongly associated with lower extremity arterial disease as expected. This is consistent with prior studies that have reported that these two conditions are two of the most important risk factors for peripheral vascular disease, thereby lending validity of the methods by which we defined disease states in our study. ${ }^{11}$

One final weakness that must be addressed is that there were significant differences in age between male cases and controls as well as between female cases and controls in the gender-stratified analyses. Specifically, among male subjects, cases were older than controls (mean age differed by approximately 3 years), whereas among female subjects, controls were older than cases (mean age differed by approximately 3 years). This may have occurred, in part, because we agematched subjects prior to gender stratification. It is possible that the age difference between cases and controls could have biased our results to some degree because the prevalence of hypothyroidism increases with age. However, we controlled for age in the multivariate analysis and still found significant associations between hypothyroidism and lower extremity arterial disease for both genders.

\section{Conclusion}

Gender is a significant effect modifier for the association between hypothyroidism and lower extremity arterial disease. The association is positive in men and negative in women. Future prospective studies that evaluate hypothyroidism as a risk factor for peripheral arterial disease should consider gender stratification in order to corroborate this finding.

\section{Disclosure}

No competing financial interests exist.

\section{References}

1. Klein I, Ojamaa K. Thyroid hormone and the cardiovascular system. N Engl J Med. 2001;344(7):501-509.

2. Fazio S, Palmieri EA, Lombardi G, Biondi B. Effects of thyroid hormone on the cardiovascular system. Recent Prog Horm Res. 2004; $59: 31-50$

3. Endo T, Komiya I, Tsukui T, et al. Re-evaluation of a possible high incidence of hypertension in hypothyroid patients. Am Heart J. 1979; 98(6):684-688.

4. Obuobie K, Smith J, Evans LM, John R, Davies JS, Lazarus JH. Increased central arterial stiffness in hypothyroidism. J Clin Endocrinol Metab. 2002;87(10):4662-4666.

5. Pearce EN. Hypothyroidism and dyslipidemia: modern concepts and approaches. Curr Cardiol Rep. 2004;6(6):451-456.

6. Becker C. Hypothyroidism and atherosclerotic heart disease: pathogenesis, medical management, and the role of coronary artery bypass surgery. Endocr Rev. 1985;6(3):432-440.

7. Ochs N, Auer R, Bauer DC, et al. Meta-analysis: subclinical thyroid dysfunction and the risk for coronary heart disease and mortality. Ann Intern Med. 2008;148(11):832-845. 
8. Rodondi N, Aujesky D, Vittinghoff E, Cornuz J, Bauer DC. Subclinical hypothyroidism and the risk of coronary heart disease: a meta-analysis. Am J Med. 2006;119(7):541-551.

9. Mayer O Jr, Simon J, Filipovský J, Plásková M, Pikner R. Hypothyroidism in coronary heart disease and its relation to selected risk factors. Vasc Health Risk Manag. 2006;2(4):499-506.

10. Hak AE, Pols HA, Visser TJ, Drexhage HA, Hofman A, Witteman JC. Subclinical hypothyroidism is an independent risk factor for atherosclerosis and myocardial infarction in elderly women: the Rotterdam Study. Ann Intern Med. 2000;132(4):270-278.

11. Norgren L, Hiatt WR, Dormandy JA, et al. Inter-society consensus for the management of peripheral arterial disease (TASC II). Eur J Vasc Endovasc Surg. 2007;33 Suppl 1:S1-S75.

12. Mya MM, Aronow WS. Increased prevalence of peripheral arterial disease in older men and women with subclinical hypothyroidism. J Gerontol A Biol Sci Med Sci. 2003;58(1):68-69.

13. Powell J, Zadeh JA, Carter G, Greenhalgh RM, Fowler PB. Raised serum thyrotropin in women with peripheral arterial disease. Br J Surg. 1987;74(12):1139-1141.

14. Owen PJ, Rajiv C, Vinereanu D, Mathew T, Fraser AG, Lazarus JH. Subclinical hypothyroidism, arterial stiffness, and myocardial reserve. J Clin Endocrinol Met. 2006;91(6):2126-2132.

15. Monzani F, Caraccio N, Kozàkowà M, et al. Effect of levothyroxine replacement on lipid profile and intima-media thickness in subclinical hypothyroidism: a double-blind, placebo-controlled study. J Clin Endocrinol Metab. 2004;89(5):2099-2106.
16. Rodondi N, Newman AB, Vittinghoff E, et al. Subclinical hypothyroidism and the risk of heart failure, other cardiovascular events, and death. Arch Intern Med. 2005;165(21):2460-2466.

17. Hirose K, Chikamori T, Hida S, et al. Prevalence of coronary heart disease in patients with aortic aneurysm and/or peripheral artery disease. Am J Cardiol. 2009;103(9):1215-1220.

18. Hertzer NR, Beven EG, Young JR, et al. Coronary artery disease in peripheral vascular patients: a classification of 1000 coronary angiograms and results of surgical management. Ann Surg. 1984; 199(2):223-233.

19. Ahto M, Isoaho R, Puolijoki H, Laipalla P, Rommo M, Kivelä SL. Prevalence of coronary heart disease, associated manifestations and electrocardiographic findings in elderly Finns. Age Ageing. 1998; 27(6):729-737.

20. Roger VL, Weston SA, Killian JM, et al. Time trends in the prevalence of atherosclerosis: a population-based autopsy study. Am J Med. 2001;110(4):267-273.

21. Danese MD, Powe NR, Sawin CT, Ladenson PW. Screening for mild thyroid failure at the periodic health examination: a decision and costeffectiveness analysis. JAMA. 1996;276(4):285-292.

22. Jónsdóttir LS, Sigfússon N, Gudnason V, Sigvaldason H, Thorgeirsson G. Do lipids, blood pressure, diabetes, and smoking confer equal risk of myocardial infarction in women as in men? The Reykjavik Study. J Cardiovasc Risk. 2002;9(2):67-76.
Vascular Health and Risk Management

\section{Publish your work in this journal}

Vascular Health and Risk Management is an international, peerreviewed journal of therapeutics and risk management, focusing on concise rapid reporting of clinical studies on the processes involved in the maintenance of vascular health; the monitoring, prevention and treatment of vascular disease and its sequelae; and the involvement of

\section{Dovepress}

metabolic disorders, particularly diabetes. This journal is indexed on PubMed Central and MedLine. The manuscript management system is completely online and includes a very quick and fair peer-review system, which is all easy to use. Visit http://www.dovepress.com/ testimonials.php to read real quotes from published authors. 